\title{
Cracking Behavior of a Concrete Arch Dam with Weak Upper Abutment
}

\author{
Lei Xu, ${ }^{1}$ Shuaizhao Jing, ${ }^{1}$ Jie Liu, ${ }^{2}$ and Yefei Huang ${ }^{1}$ \\ ${ }^{1}$ College of Water Conservancy and Hydropower Engineering, Hohai University, Nanjing 210098, China \\ ${ }^{2}$ Chongqing Surveying and Design Institute of Water Resources, Electric Power and Architecture, Chongqing 400020, China \\ Correspondence should be addressed to Lei Xu; leixu@hhu.edu.cn
}

Received 30 April 2017; Revised 21 October 2017; Accepted 14 November 2017; Published 28 November 2017

Academic Editor: Fabrizio Greco

Copyright (c) 2017 Lei Xu et al. This is an open access article distributed under the Creative Commons Attribution License, which permits unrestricted use, distribution, and reproduction in any medium, provided the original work is properly cited.

\begin{abstract}
The cracking behavior and failure mode of a $78 \mathrm{~m}$ high concrete double-curvature arch dam with weak upper abutment are investigated through performing cracking analysis. The mechanical behavior of concrete is simulated using a smeared crack model, in which a combination of the compression yield surface and the crack detection surface with a damaged elasticity concept is employed to describe the failure of concrete. The arch dam with practical mechanical properties of the upper and lower abutments is firstly studied with emphasis on its cracking behavior during overloading. Then, a comprehensive sensitivity analysis is carried out to investigate the influence of the ratio of the mechanical properties of upper abutment to those of lower abutment on dam failure with prime attention placed on the failure mode. Simulation results indicate the adopted smeared crack model is well-suited to the crack analysis of concrete arch dam. It is shown that cracking is localized around the interface between upper and lower abutments, which leads to a fast crack growth in the through-thickness direction of dam and finally causes the dam failure. Furthermore, the sensitivity analysis presents three types of failure modes corresponding to different ratio value, wherein Modes II and III should be avoided since the weak upper abutment plays a predominant role in the cracking and failure of concrete arch dam.
\end{abstract}

\section{Introduction}

Concrete arch dam is one of the most prevalent dam types worldwide, and its cracking behavior remains an active research focus of interest due to the unacceptable failure consequences [1-3]. As is well known, the structural response of a concrete arch dam is greatly influenced by rock abutment. From the design point of view, the rock abutment with uniform mechanical properties and sufficient strength and stiffness is preferred. However, attributed to the complexity of in situ geological conditions, rock abutments with unfavorable features such as nonuniformity, discontinuity, low mechanical properties, and etcetera are frequently encountered in practice $[1,4]$. In this regard, it is necessary to investigate the potential cracking behavior and failure mode of the concrete arch dam with unfavorable abutment, which can further serve as the basis of the engineering decision making related to the abutment reinforcement.

Among various geological defects of rock abutment which might be encountered in practice, nonuniformity is a typical one. For instance, the stiffness of right and upper abutment of Jinping double-curvature thin arch dam, the highest concrete arch dam at present, is much lower than that of left and low abutment [5]. Motivated by practical needs, several related research works have been carried out with the aim of studying the influence of nonuniform abutment on dam structural behaviors. Remarkable are the contributions made by Zhou and coworkers [6] who investigated the influences of asymmetry of arch dam foundation using both experimental and numerical methods, Yu and Ren [5] who evaluated the global safety of a concrete arch dam with geological asymmetry conditions by conducting finite element simulations, Ning and coworkers [7] who discussed the effects of engineering reinforcement measures aiming to reduce the disadvantages of nonuniform arch dam abutment, and Yang and coworkers [8] who carried out three geological model tests for studying the failure behavior of a concrete arch dam with nonuniform abutment. However, most of the simulation works consider concrete arch dam to behave elastically, and consequently the cracking behavior and failure 
mode of concrete arch dam cannot be captured. Limited studies on the cracking behavior of concrete arch dam can be found in $[9,10]$ in which the rock foundation is assumed to be rigid and in [11, 12] in which the concrete arch dam is treated as a crown cantilever and is analyzed using the linear elastic fracture mechanics method. Moreover, to the best of our knowledge, the study on the influence of the ratio of mechanical properties of weak abutment and those of strong abutment on the cracking behavior and failure mode, which can provide an extensive knowledge of the structural failure of the concrete arch dam with nonuniform abutment in a general sense, has been rarely detailed in past research works.

It has been well recognized that cracking should be taken into account when investigating the failure behavior of concrete structures [13-15]. Up to date, the macroscale cracking simulation approaches can be mainly grouped into two types: the discrete cracking approach [16-18] and the smeared cracking approach $[19,20]$. For the former one, cracks in concrete are treated as geometrical discontinuities, and therefore a discrete crack model (DCM) such as the known fictitious crack model (FCM) proposed by Hillerborg and coworkers [21] is needed to model the cracking behavior in an explicit way. Unlike the discrete crack approach, the smeared cracking approach, implemented by employing a continuum constitutive model such as the crack band theory proposed by Bažant and Oh [22], describes the influences of cracks on the overall concrete behavior in an implicit (also termed "smeared") way. Although the discrete cracking approach can track the crack propagating process, there are still some difficulties when applying this approach to the cracking analysis of practical concrete arch dam such as the interaction of multiple cracks, the determination of crack propagating direction in three-dimensional case, and the numerical convergence issue. With this in mind, the smeared cracking approach is employed in the present work.

In this study, the cracking behavior of a $78 \mathrm{~m}$ high concrete double-curvature arch dam, which has typical nonuniform rock foundation with upper abutment weaker than lower abutment, is performed by adopting a smeared crack model, and, moreover, the influence of the ratio of mechanical properties of upper abutment and those of lower abutment on the dam structural response is discussed with emphasis on the failure mode. The rest of this paper is organized as follows: Section 2 presents the formulation of the concrete smeared crack model; an overview of the geological conditions of the dam and the finite element modeling strategy are given in Section 3; in Section 4, the arch dam with practical mechanical properties of the upper and lower abutments is first analyzed with a focus on dam cracking process during overloading, and then a comprehensive sensitivity analysis is carried out to investigate the influence of the ratio of the mechanical properties of upper abutment to those of lower abutment on the dam failure mode; finally, the study is summarized with conclusions in Section 5.

\section{Concrete Smeared Crack Model}

Several smeared crack models for concrete have been proposed to describe concrete cracking behavior at the macroscale constitutive level, and a detailed discussion of different types of smeared crack models was made by Rots and Blaauwendraad [19]. In the following research, the smeared crack concrete model provided in ABAQUS [23], which describes the compression behavior of concrete within the framework of plasticity and employs a crack detection surface to determine the formation of a crack and the corresponding cracking orientation, is adopted. The basic formulation of the model is given as follows (see [21, 24, 25] for more details).

To determine concrete yield under compression, a yield surface in stress space is introduced as

$$
f_{c}=q-\sqrt{3} a_{0} p-\sqrt{3} \tau_{c}=0,
$$

where $p$ and $q$ are the effective pressure stress and the Mises equivalent deviatoric stress, respectively; $a_{0}$ is a constant used to define the shape of the yield surface, which can be calculated form a given value of $r_{\mathrm{bc}}^{\sigma}$ (the ratio of the biaxial compressive strength $\sigma_{\mathrm{bc}}^{u}$ to the uniaxial compressive strength $\left.\sigma_{c}^{u}\right)$; and $\tau_{c}$ is another parameter used to describe concrete compression hardening behavior.

Based on (1) and considering the case of uniaxial compression with compressive stress $\sigma_{c}$, in which $p=(1 / 3) \sigma_{c}$ and $q=\sigma_{c}, \tau_{c}$ can be expressed as

$$
\tau_{c}=\left(\frac{1}{\sqrt{3}}-\frac{a_{0}}{3}\right) \sigma_{c} .
$$

From (2), concrete hardening can be directly characterized by the relation between the uniaxial compressive stress and the corresponding plastic strain.

The associated flow is adopted in the concrete smeared crack model, and the incremental plastic strain $d \varepsilon_{c}^{\mathrm{pl}}$ is defined as

$$
d \varepsilon_{c}^{\mathrm{p}}=d \lambda_{c}\left(1+c_{0}\left(\frac{p}{\sigma_{c}}\right)^{2}\right) \frac{\partial f_{c}}{\partial \sigma}
$$

in which $d \lambda_{c}$ is the incremental plastic multiplier and $c_{0}$ is a constant determined by a given value of $r_{\mathrm{bc}}^{\varepsilon}$ (the ratio of the total plastic strain in biaxial compression to that in uniaxial compression).

When the stress state of concrete is predominantly tensile, cracking dominates the mechanical behavior of concrete. For the purpose of identifying the crack formation, a crack detection surface is defined in the stress space as

$$
f_{t}=q-\left(3-b_{0} \frac{\sigma_{t}}{\sigma_{t}^{u}}\right) p-\left(2-\frac{b_{0}}{3} \frac{\sigma_{t}}{\sigma_{t}^{u}}\right) \sigma_{t}=0,
$$

where $\sigma_{t}^{u}$ is the failure stress in uniaxial tension; $b_{0}$ is a constant defined from the value of the tensile failure stress in a state of biaxial stress when the other nonzero principle stress is set equal to $-\sigma_{c}^{u}$; and $\sigma_{t}$ is the equivalent tensile stress used to describe the tension softening. To link the failure stress in uniaxial tension to that in uniaxial compression, a ratio denoted by $r_{t}^{\sigma}$ is introduced as a model parameter, and then $\sigma_{t}^{u}$ is expressed as $r_{t}^{\sigma} \sigma_{c}^{u}$. It should be noted that the stress components associated with existing cracks are not taken into account when calculating the value of $p$ and $q$ in (4), which 


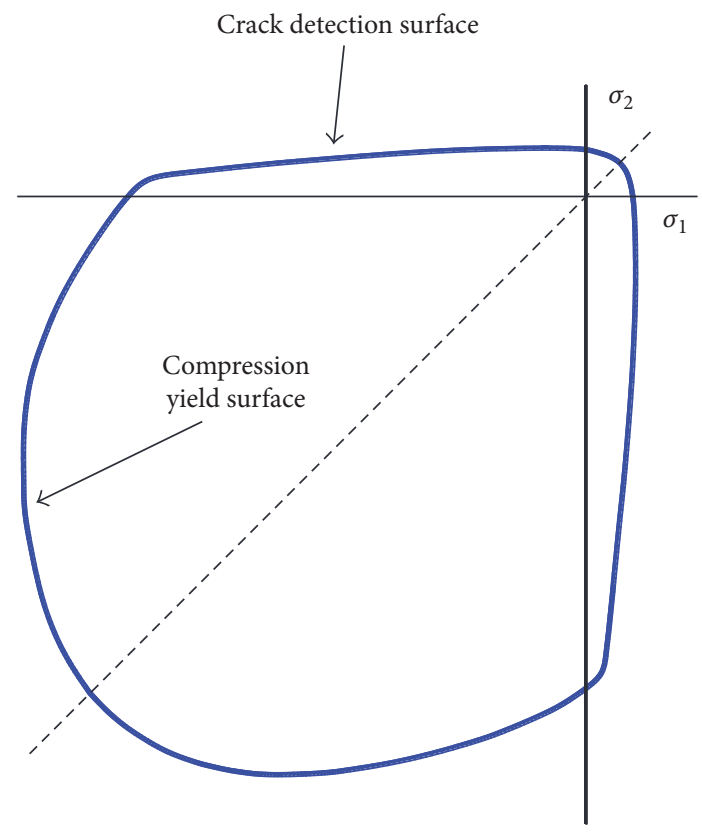

FIGURE 1: Concrete failure surfaces in plane stress.

means the new crack plane is assumed to be orthogonal to the existing ones.

Similar to the modeling strategy in compression regime, the associated flow rule is also employed in tension regime, which is given as

$$
d \varepsilon_{t}^{\mathrm{pl}}=d \lambda_{t} \frac{\partial f_{t}}{\partial \sigma}
$$

in which $d \varepsilon_{t}^{\mathrm{pl}}$ is the incremental tension plastic strain and $d \lambda_{t}$ is the incremental plastic multiplier. Figure 1 illustrates concrete failure surfaces that comprise compression yield surface and crack detection surface in the case of plane stress.

For a certain stress state, when (4) is satisfied, cracking is considered to take place, and the crack orientation is taken to be the direction of that part of the maximum principal plastic strain increment conjugate to the crack detection surface, which is orthogonal to the directions of any existing cracks.

After cracking, oriented damaged elasticity (smeared cracking) [19] is used to describe the postfailure behavior of the concrete with open cracks. More specifically, the relation between the normal stress and normal strain on the crack plane is controlled by the damaged elastic modulus, which decreases with the increase of normal strain by following a prescribed tension softening law (typically, obtained from uniaxial tension tests), and, on the other hand, the shear behavior on the crack plane is also dominated by a varying shear modulus, which is assumed to linearly decrease from its origin value to zero with the increase of the normal tensile strain.

Compared to DCMs, the aforementioned concrete smeared crack model, which is mainly formulated within the framework of traditional elastoplasticity and takes use of the concept of damaged elasticity to describe the material stiffness degradation due to tensile cracking, retains the geometrical continuity of numerical models, which is traditionally considered as a prime merit from a computational strategy point of view. Meanwhile, many practical applications have shown that it can simulate concrete cracking behavior in a reasonable fashion owing to the combination of plastic softening and damaged elasticity $[13,14,19]$. To this end, the concrete smeared crack model presented in this section is applied to investigate the cracking behavior of a concrete arch dam with weak upper abutment.

\section{Finite Element Model}

In this section, the geological conditions of a practical concrete arch dam with weak upper abutment are briefly introduced, followed by the description of the finite element modeling strategy. Then, the mechanical properties of both dam concrete and the upper and lower rock abutments are given. Finally, the loading process in FE simulation is discussed.

3.1. Engineering Geological Conditions. The concrete doublecurvature arch dam with parabola horizontal arch ring, situated in southwestern China, has $78 \mathrm{~m}$ height and $224.68 \mathrm{~m}$ arch length of dam crest. The geological cross section and the excavation line of dam abutment are illustrated in Figure 2, from which it is clearly shown that the dam foundation is composed of multiple horizontal rock layers with different thicknesses. According to the geological survey, these rock layers can be in general divided into two groups: one with low mechanical properties and the other one with high mechanical properties. From the in situ experimental results, the former one consists of the rock layers denoted by $\epsilon_{2 g}^{2-3}$, $\epsilon_{2 g}^{2-4}, \epsilon_{2 g}^{2-5}$, and $\epsilon_{2 g}^{2-6}$, respectively, while the rock layers denoted by $\epsilon_{2 g}^{2-1}$ and $\epsilon_{2 g}^{2-2}$, respectively, belong to the latter one. Being aware of the relative position between the dam and rock layers, it can be found that the upper dam abutment in the altitude range 441 to $480 \mathrm{~m}$ is mechanically weaker than the lower dam abutment in the altitude range 480 to $510 \mathrm{~m}$ (see Figure 3 for pictorial representation), which herein can be viewed as a geological defect since the preferred overall uniformity of rock foundation is obviously violated.

3.2. Finite Element Mesh and Mechanical Properties. To perform the cracking analysis of the concrete arch dam with weak upper abutment, the nonlinear finite element (FE) method is employed in the present work, and the three-dimensional FE numerical model is first generated through mesh discretization. Figures 4 and 5 present the dam mesh and the dam-rock foundation mesh, which are mainly composed of 8-node hexahedral elements. In order to better capture the cracking behavior, the arch dam is discretized by a relatively fine mesh with typical element size of $1.5 \mathrm{~m}$. The number of nodes and elements of dam mesh is 24660 and 21064 , respectively, while the number of nodes and elements of the entire FE mesh is 154787 and 141831, respectively.

As stated in Section 2, the smeared crack model is adopted in FE simulation to describe the mechanical behavior of dam concrete with the prime purpose of capturing the dam 


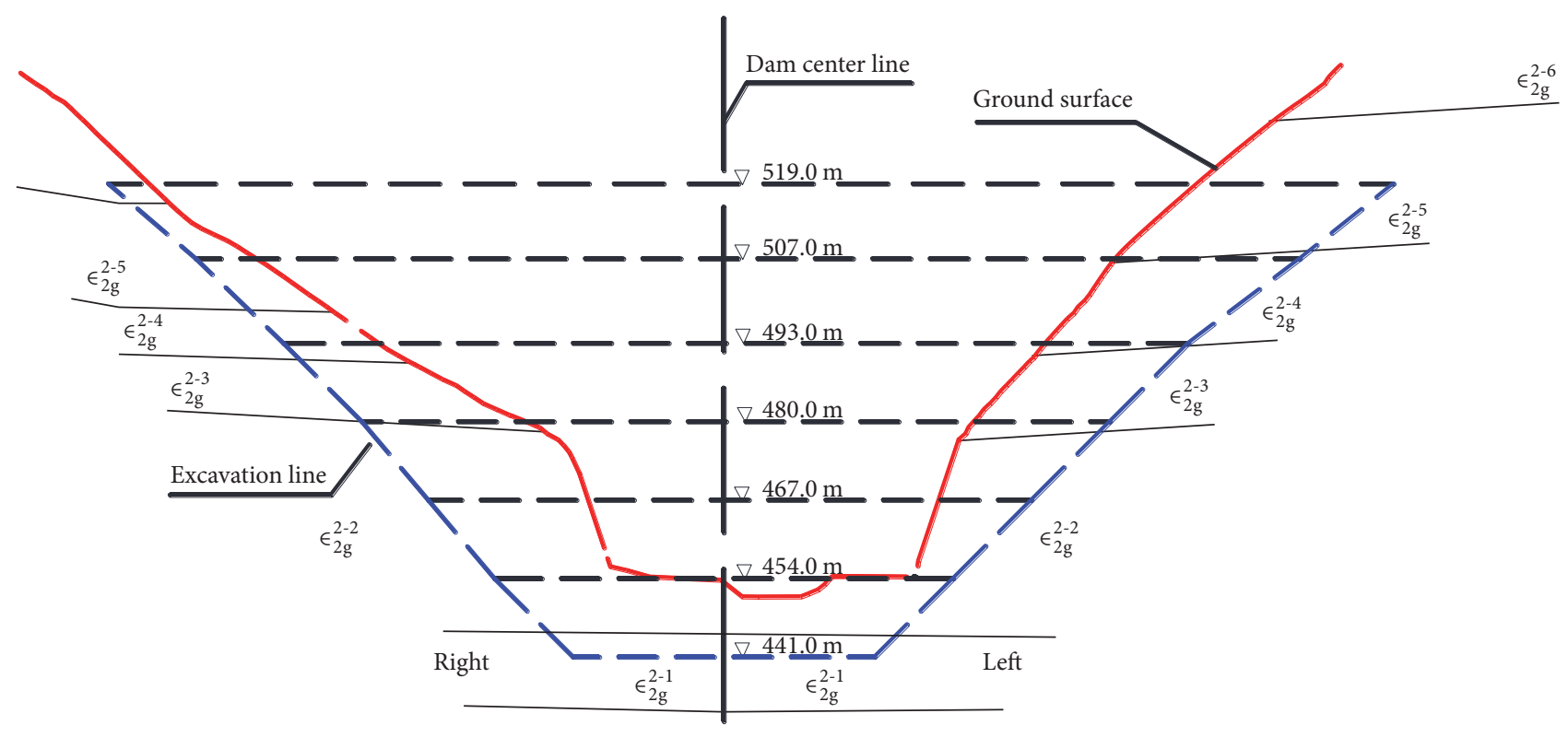

FIGURE 2: Geological profile.

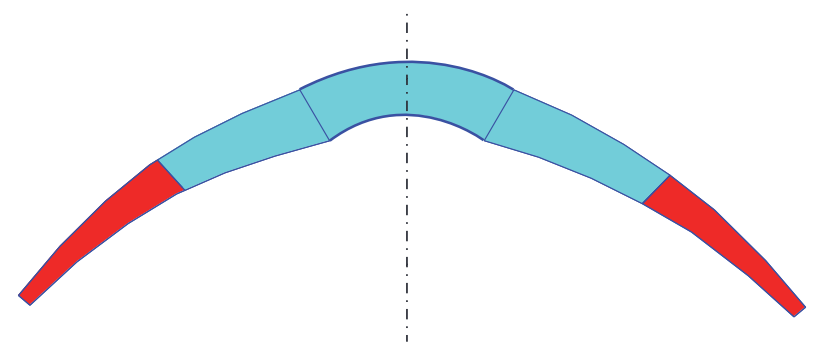

Weak abutment

Strong abutment

FIGURE 3: Rock quality distribution of the dam abutment.

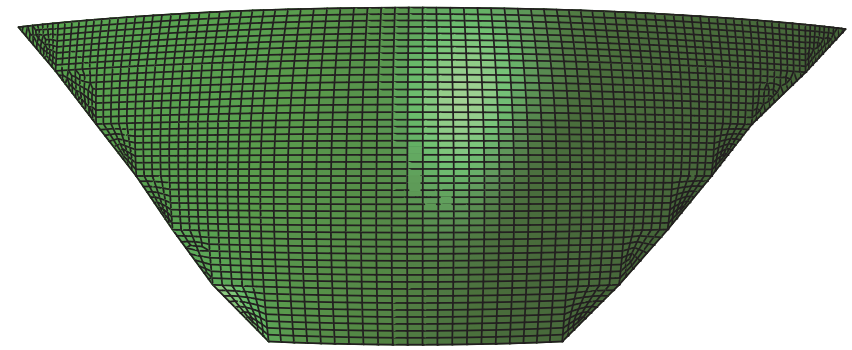

FIGURE 4: FE mesh of the concrete arch dam.

cracking behavior. The model parameters, which control the concrete mechanical behavior under loading, include elastic modulus, $E$, Poisson's ratio, $\mu$, failure stress under uniaxial compression, $\sigma_{c}^{u}$, the ratio of failure stress under biaxial compression to $\sigma_{c}^{u}, r_{\mathrm{bc}}^{\sigma}$, the ratio of the failure stress under uniaxial tension to $\sigma_{c}^{u}, r_{t}^{\sigma}$, and the ratio of total plastic strain under biaxial compression to that under uniaxial compression, $r_{\mathrm{bc}}^{\varepsilon}$. Additionally, the compression hardening should be defined as the relation between stress and plastic strain in the uniaxial compression sense, and the relation between stress and strain subtracted by that corresponding to the failure tensile stress should also be given in the uniaxial tension sense for describing the concrete softening due to cracking.

According to the concrete strength grade, C20, specified in the dam design, the above mechanical parameters together 


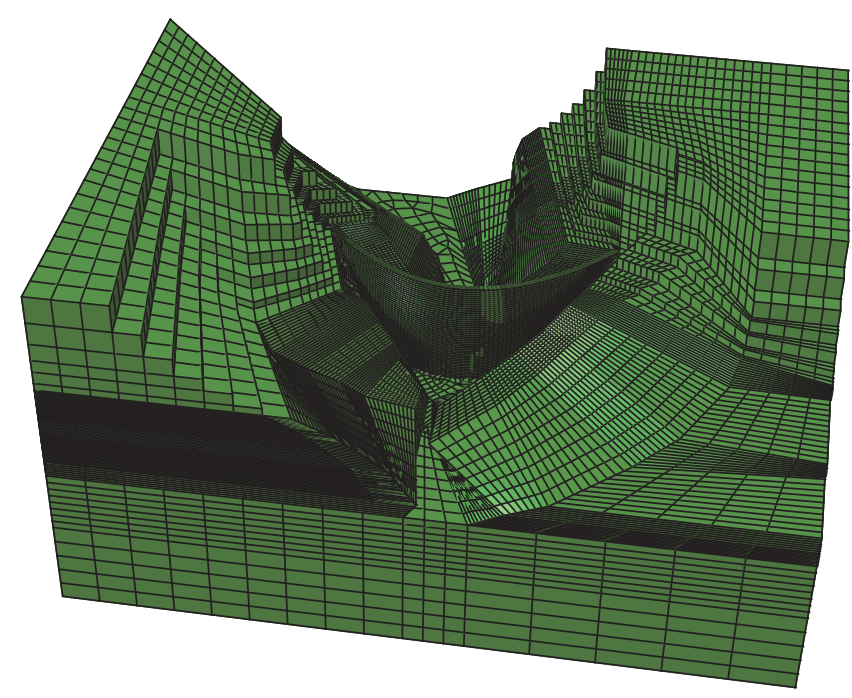

FIGURE 5: FE mesh of the dam body and rock foundation.

TABLE 1: Mechanical parameters of dam concrete.

\begin{tabular}{lccccc}
\hline$E(\mathrm{MPa})$ & $\mu(-)$ & $\sigma_{c}^{u}(\mathrm{MPa})$ & $r_{\mathrm{bc}}^{\sigma}$ & $r_{t}^{\sigma}$ & $r_{\mathrm{bc}}^{\varepsilon}$ \\
\hline 25500 & 0.167 & 21.6 & 1.16 & 0.09 & 1.28 \\
\hline
\end{tabular}

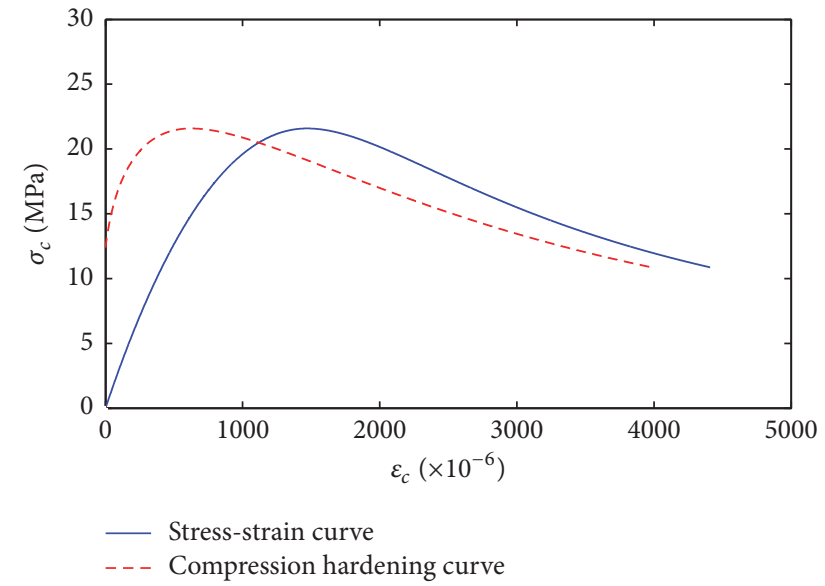

FIGURE 6: Total stress-strain relation under uniaxial compression and compression hardening curve of dam concrete.

with the associated compression hardening and tension softening curves can be obtained with ease. The mechanical parameters of dam concrete are listed in Table 1, and Figures 6 and 7 show the compression hardening curve (used to define $\tau_{c}$ ) and the tension softening curve (for the definition of $\sigma_{t}$ ), respectively, obtained from Chinese code GB 500102002 (code for design of concrete structures). Moreover, the density of dam concrete $\rho$ is set to $2400 \mathrm{~kg} / \mathrm{m}^{3}$.

While, for rock foundation, the elastoplastic constitutive model using the classical Drucker-Prager yield criterion is employed to describe its mechanical behavior, the physical and mechanical parameters (i.e., density $\rho_{r}$, elastic modulus $E_{r}$, Poisson's ratio $\mu_{r}$, friction coefficient $f_{r}$, and cohesive

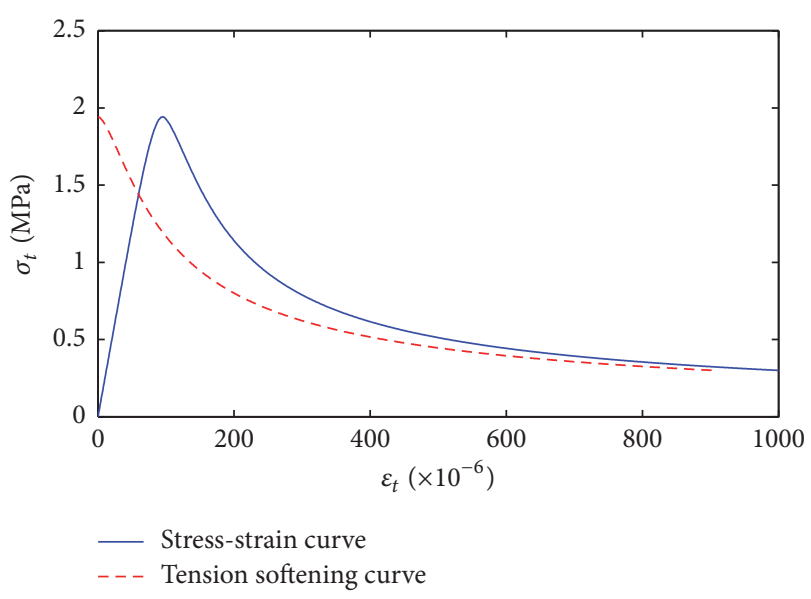

FIgURE 7: Total stress-strain relation under uniaxial tension and tension softening curve of dam concrete.

strength $c_{r}$ ) of the upper and lower rock abutments are given in Table 2.

3.3. Loading Simulation. For the sake of gaining the real structural response of the arch dam in construction and operation, the simulated loading process in nonlinear FE simulation should generally coincide with the practical one. To this end, first the initial geostress field, which is considered to be self-weight stress field according to engineering geological investigation, is imported in simulation, and then gravity load is exerted on the dam body. Afterwards, water loads are applied, followed by the temperature load and sediment pressure. Finally, with the aim of studying the cracking 
TABLE 2: Physical and mechanical parameters of rock abutments.

\begin{tabular}{lccccc}
\hline & $\rho_{r}\left(\mathrm{~kg} / \mathrm{m}^{3}\right)$ & $E_{r}(\mathrm{MPa})$ & $\mu_{r}(-)$ & $f_{r}(-)$ & $c_{r}(\mathrm{MPa})$ \\
\hline Upper abutment & 2580 & 1750 & 0.32 & 0.55 & 0.20 \\
Lower abutment & 2640 & 8750 & 0.22 & 0.95 & 0.65 \\
\hline
\end{tabular}

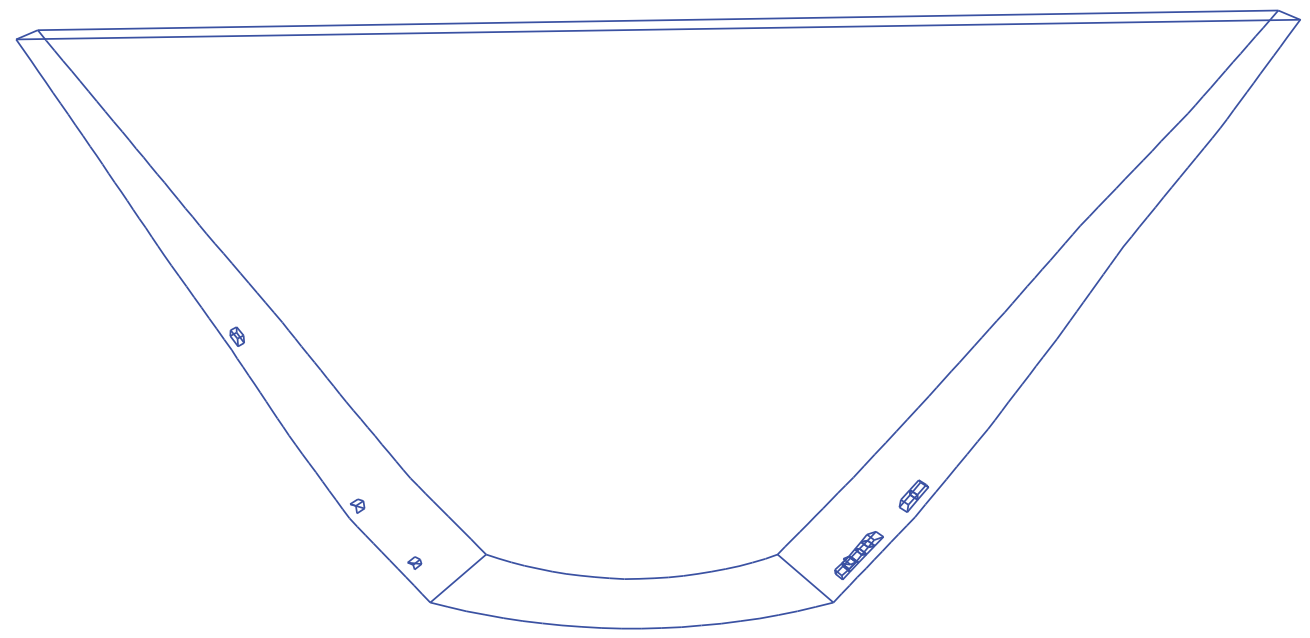

FIGURE 8: Distribution of cracked elements in dam when increasing the upstream water pressure by 0.4 times.

behavior of the concrete arch dam, overloading method is employed by amplifying the water pressure applied on the upstream surface of dam stepwise.

With respect to the overloading, there are mainly two approaches: the water density increasing approach and the water level increasing approach. Despite the fact that the overlevel flood can be considered to be one of the potential causes resulting in dam failure, the great rise of upstream water level still seems to be impractical due to the water discharge including crest overflow [1]. Furthermore, originated from the fact that the performance deterioration of dam concrete is the main reason for the failure of dam structure under external loading conditions [26], the distribution pattern of upstream water pressure during the overloading process should be consistent with that in the operation period for the sake of preserving the realistic failure mode of the concrete arch dam to a great extent. Consequently, the water density increasing approach, which can be considered as an indirect way to model the dam failure caused by the material deterioration and has been increasingly used in the safety assessment of concrete arch dam [13-15], is adopted in the present work.

Moreover, it is worth noting that hydraulic fracturing plays an important role in the further propagation of the initial cracks caused by various factors in high concrete dams. However, since the dam height in this study is relatively small (78 meters) and the emphasis is mainly placed on the influences of weak abutment, the effect of hydraulic fracturing on cracking behavior is not taken into consideration in the numerical simulations.

\section{Results and Discussion}

In this section, the failure behavior of the concrete arch dam obtained from the FE simulation using practical mechanical parameters of rock abutments (listed in Table 2) is presented and discussed with focus placed on cracking process during overloading. After that, in order to investigate the influence of the ratio (hereafter referred to as $R$ ) of the mechanical properties of the upper abutment to those of the lower abutment on dam cracking behavior, a sensitivity analysis is performed with emphasis on the failure mode of dam.

4.1. Cracking Behavior. Figures 8-15 illustrate the distributions of cracked elements in dam at different overloading stages. It is shown that dam cracking is initiated at the upstream ends of arch rings close to dam bottom (see Figure 8 ) when increasing the water pressure by 0.4 times, and crack propagates upwards and downwards when the water pressure further increases. Due to the reduction of arch action as a result of the arch ring cracking and the increasing water pressure, cracks appear at the dam bottom and propagate from middle to both left and right sides (see Figures 9, 10, and 11), and consequently a continuous cracking zone is formulated in the upstream part of lower dam, as shown in Figure 12. Furthermore, attributed to the stress concentration taking place during sustained overloading as expected, cracking is localized around the interface between upper weak abutment and lower abutment, leading to a fast crack growth in the through-thickness direction of dam, as depicted in Figures 13 and 14. The final distribution of 


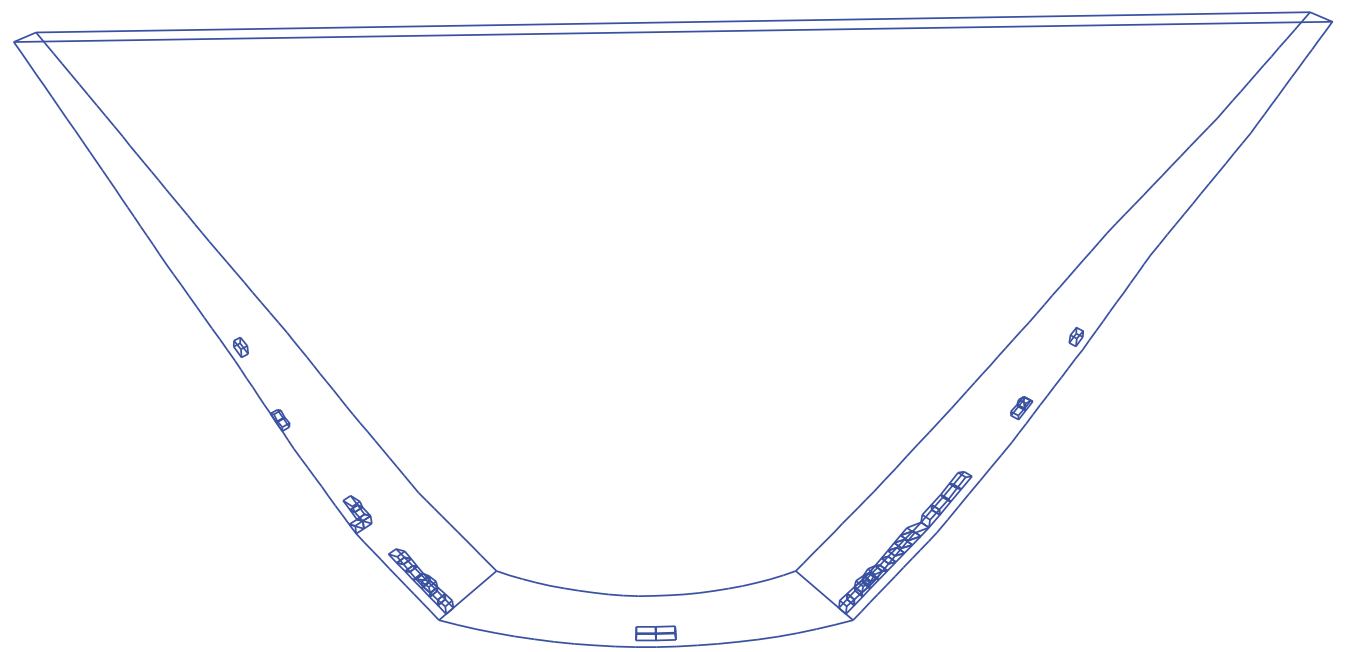

FIgURE 9: Distribution of cracked elements in dam when increasing the upstream water pressure by 0.6 times.

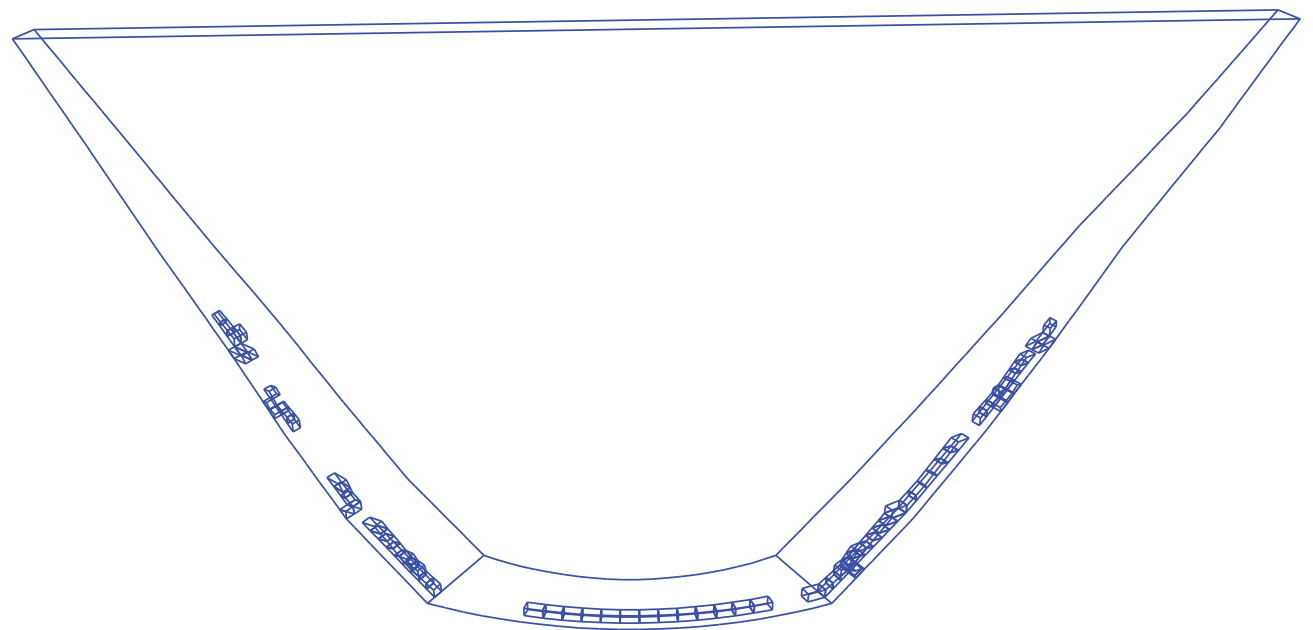

FIGURE 10: Distribution of cracked elements in dam when increasing the upstream water pressure by 0.8 times.

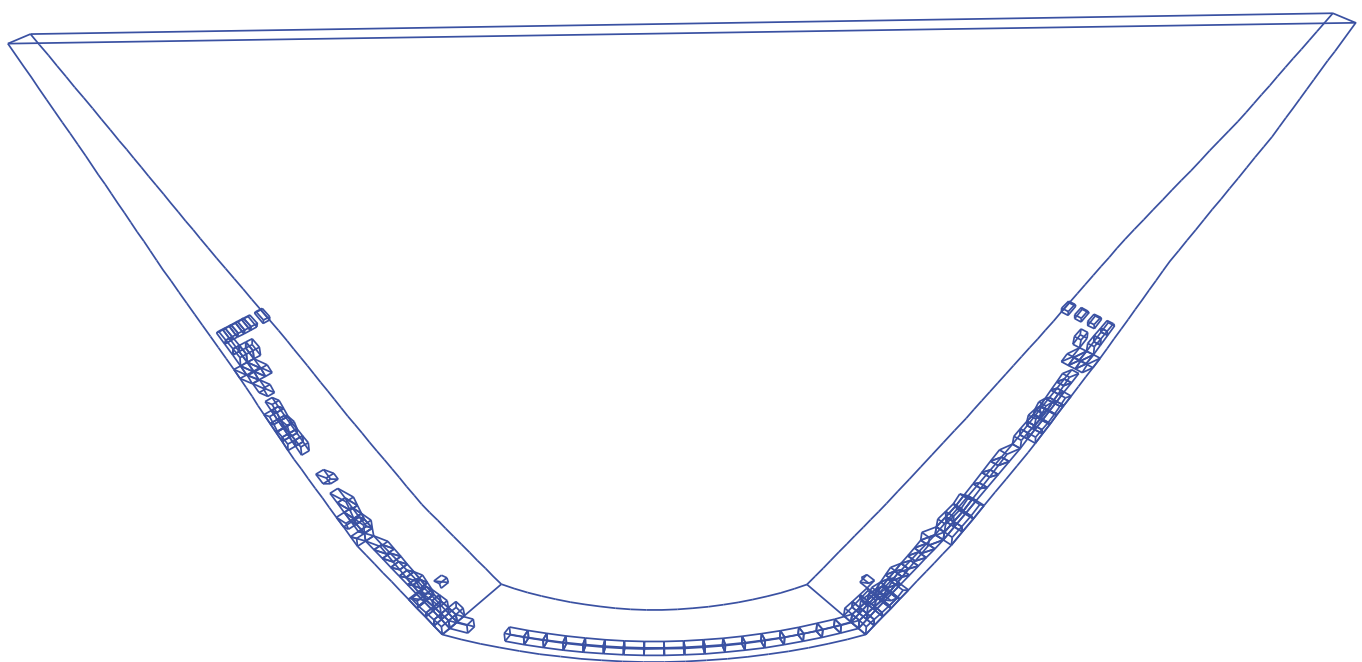

FIGURE 11: Distribution of cracked elements in dam when increasing the upstream water pressure by 1.0 times. 


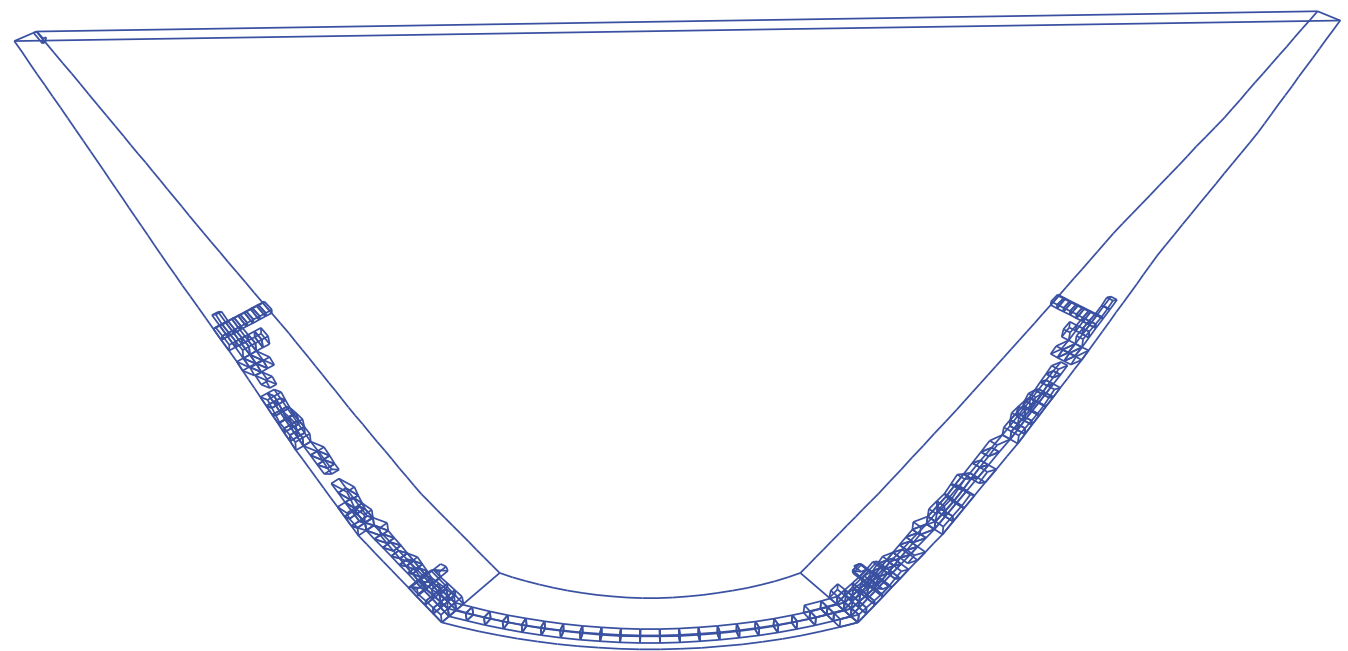

FIGURE 12: Distribution of cracked elements in dam when increasing the upstream water pressure by 1.2 times.

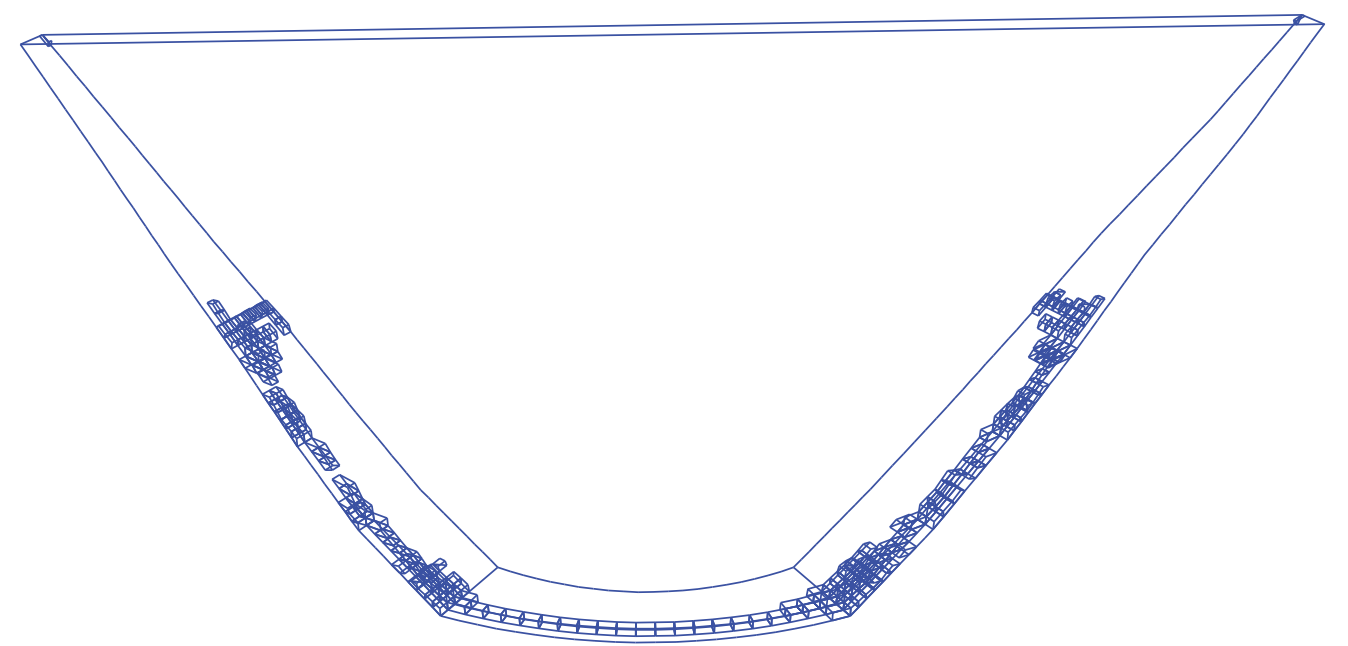

FIGURE 13: Distribution of cracked elements in dam when increasing the upstream water pressure by 1.4 times.

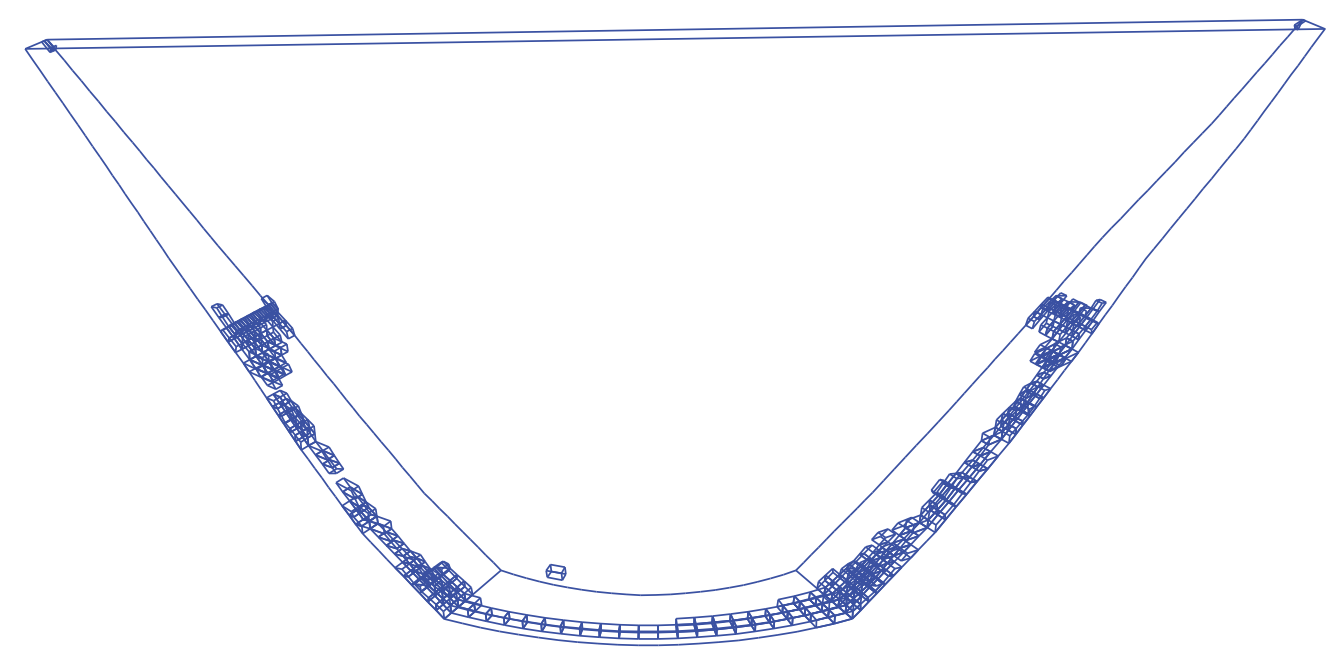

FIGURE 14: Distribution of cracked elements in dam when increasing the upstream water pressure by 1.5 times. 


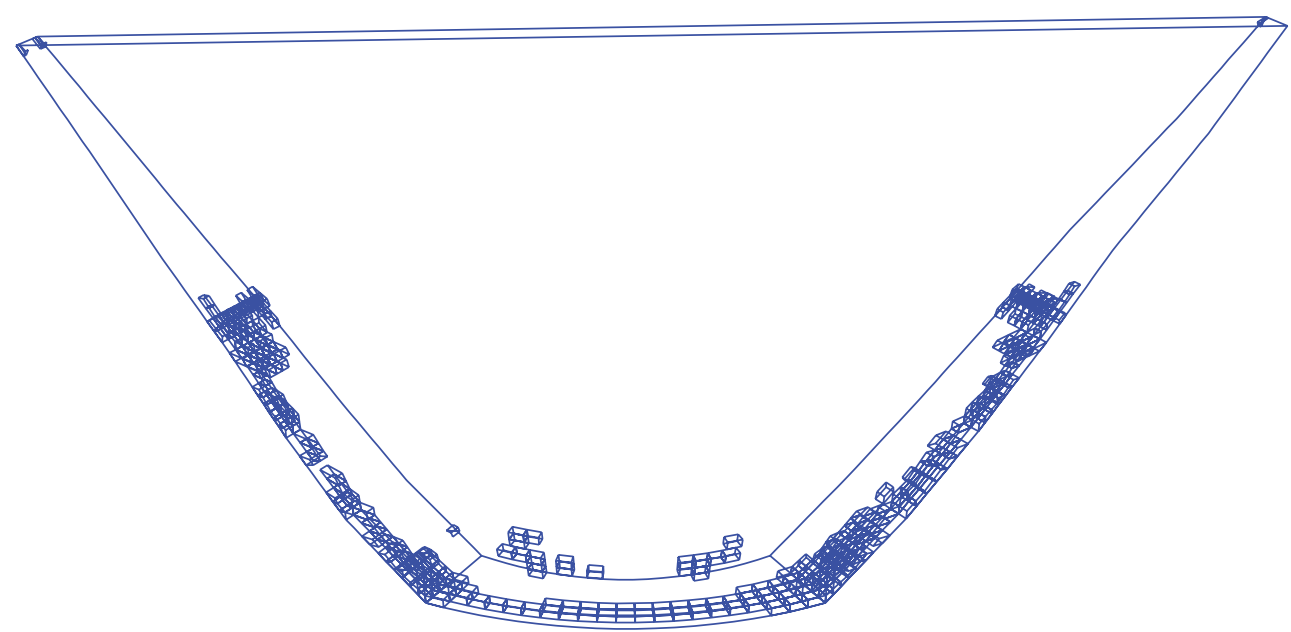

FIGURE 15: Distribution of cracked elements in dam when increasing the upstream water pressure by 1.6 times.

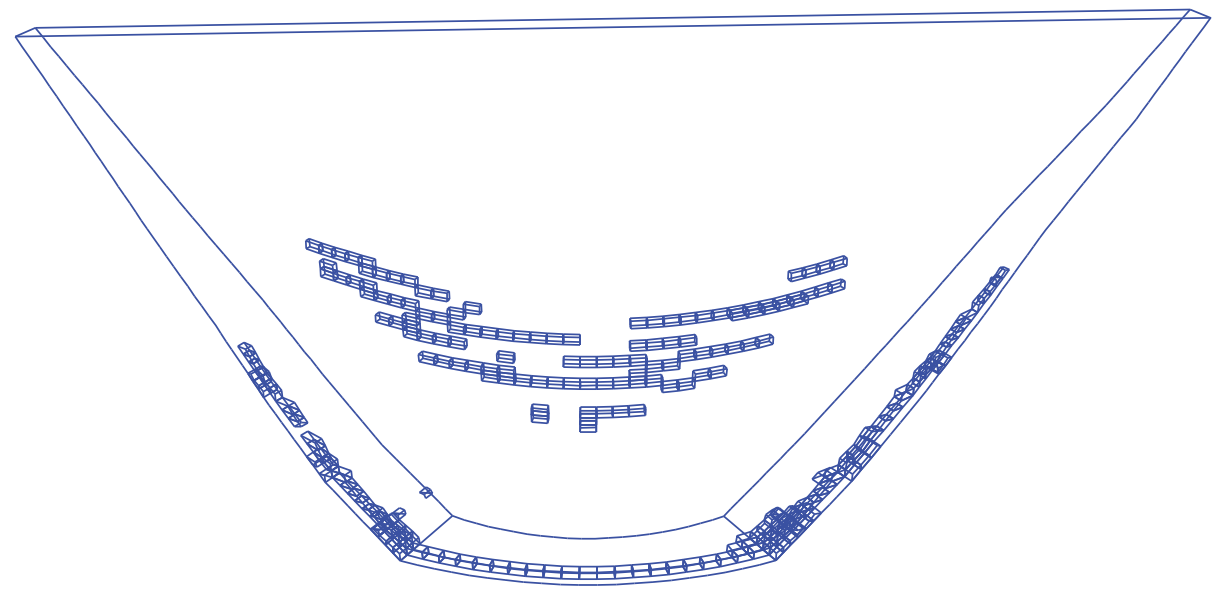

FIGURE 16: Distribution of cracked elements in dam when $R$ is equal to 1.0.

cracked elements in dam is demonstrated in Figure 15, and the corresponding water pressure is increased by 1.6 times. In addition, it can be observed that there is no cracking at the ends of upper arch rings and the central part of the arch dam, which is attributed to the fact that compared to the lower abutment the elastic modulus of upper abutment is pretty low while the strength is not.

It must be noted that although the maximum load reached in simulation cannot be undoubtedly viewed as the load-carrying capacity of the arch dam as accurately tracking the peak load of such a complex structure system remains an open issue using the implicit FE computational framework, the obtained simulation results can still be used to predict the cracking pattern and failure mode of the concrete arch dam under overloading.

4.2. Sensitivity Analysis. In the sensitivity analysis, the practical mechanical parameters of the lower abutment are kept unchanged, whereas the mechanical parameters of the upper abutment vary according to the value of $R$. Five FE simulations, which correspond to the value of $R$ equal to 1.0,
$0.7,0.5,0.3$, and 0.1 , respectively, are performed. It should be noted that only $E_{r}$, friction coefficient $f_{r}$, and cohesive strength $c_{r}$ of the upper abutment are proportionally reduced, while Poisson's ratio for each case is selected within the range 0.22 to 0.35 by taking the specified deformation and strength parameters into consideration.

Regarding the situation with $R$ equal to 1.0, namely, the upper and lower abutments with the same mechanical properties, cracking first takes place at the upstream ends of the lower arch rings, and then the upstream part of dam bottom suffers from cracking as a result of the weakened arch action attributed to the arch ring cracking. With the sustained increase of water pressure, cracking appears at the upstream central region of dam due to the stress relaxation and the subsequent load transfer resulting from the previous cracking behavior. The final distribution of cracked elements in dam for $R$ equal to 1.0 is depicted in Figure 16, and the corresponding water pressure is increased by 2.0 times.

In the case of $R=0.7$, as the upper abutment is weaker than the lower abutment, a larger proportion of structural loads is sustained by the lower part of dam compared to the 


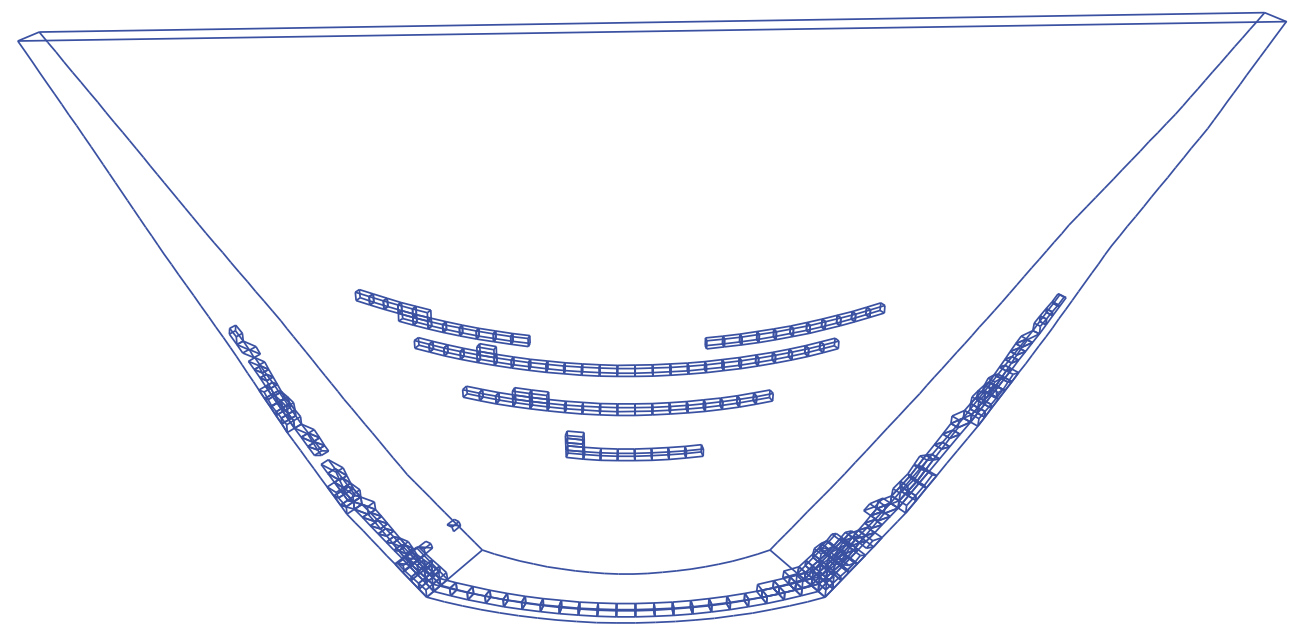

Figure 17: Distribution of cracked elements in dam when $R$ is equal to 0.7 .

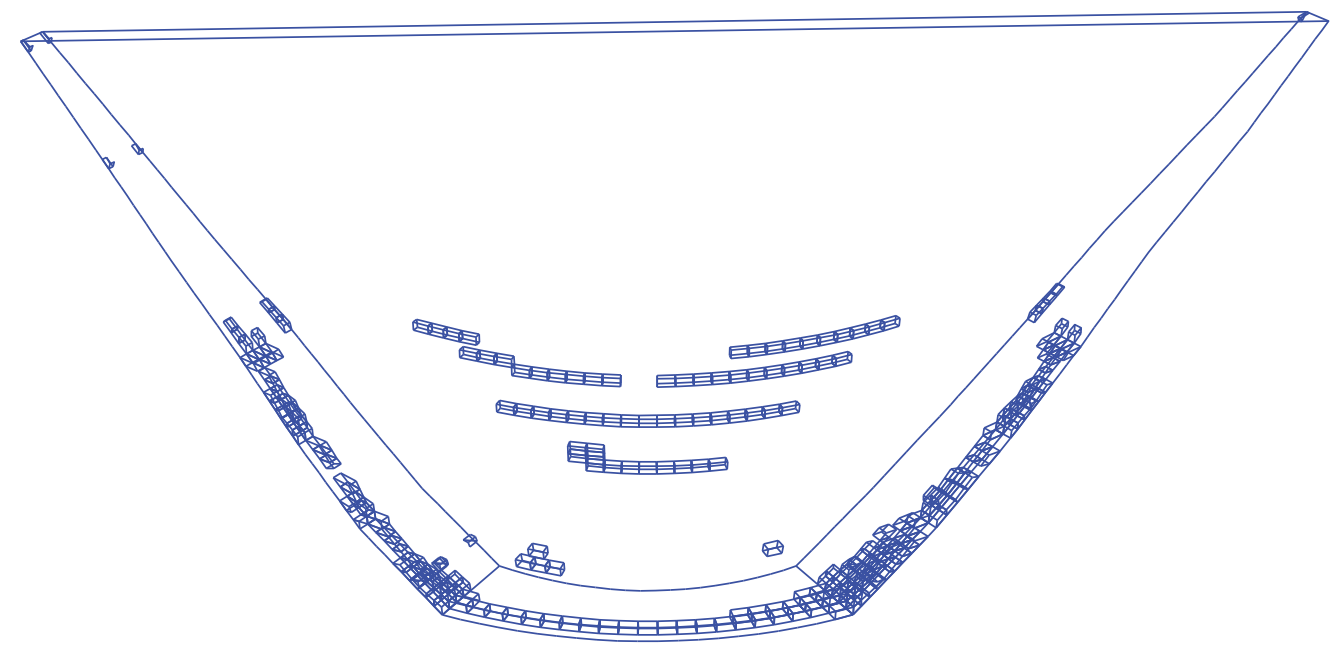

Figure 18: Distribution of cracked elements in dam when $R$ is equal to 0.5 .

case of $R=1.0$, resulting in more cracks at the upstream ends of the lower arch rings and the upstream part of dam bottom at the same loading level. On the other hand, cracks at the upstream central region of dam become less due to the stiffness decrease of upper dam resulting from the relatively weak upper abutment. On the whole, however, the dam cracking behavior and failure mode in this case resembles that with uniform abutment (see Figure 17 for the final crack distribution with the corresponding water pressure increased by 1.93 times).

Compared to the case of $R=0.7$, more cracking takes place at the upstream ends of the lower arch rings and the upstream part of dam bottom for $R=0.5$, while the upstream central region of dam suffers from less cracking as expected. The final distribution of cracked elements in dam is illustrated in Figure 18, which corresponds to the applied maximum water pressure increased by 1.85 times. It is found that the dam cracking and failure mode remain similar to the aforementioned two cases $(R=1.0$ and 0.7$)$. For this kind of failure mode (referred to as Mode I), although the upper abutment is weaker, its influence on the dam failure behavior can be considered to be trivial when noticing that the failure mode and the maximum water pressure reached during overloading only vary to a small extent. In Mode I, the failure behavior of the arch dam is mainly controlled by the interaction between dam and lower abutment.

The adopted mechanical parameters of upper abutment when $R=0.3$ are close to their practical ones in a general sense, and therefore the final distribution of cracked elements in this case (the corresponding water pressure is increased by 1.2 times) shown in Figure 19 is also similar to that presented in Section 4.1, which is different from those in the aforementioned three cases. However, the maximum water pressure reached in this situation decreases to a large extent compared to that using the practical mechanical parameters, which might be caused by the employed lower friction coefficient. Distinguished from Mode I, the failure mode similar to those in this case and Section 4.1 is called Mode II, in which the dam failure is dominated by the interaction between dam and both the upper and lower abutments. 


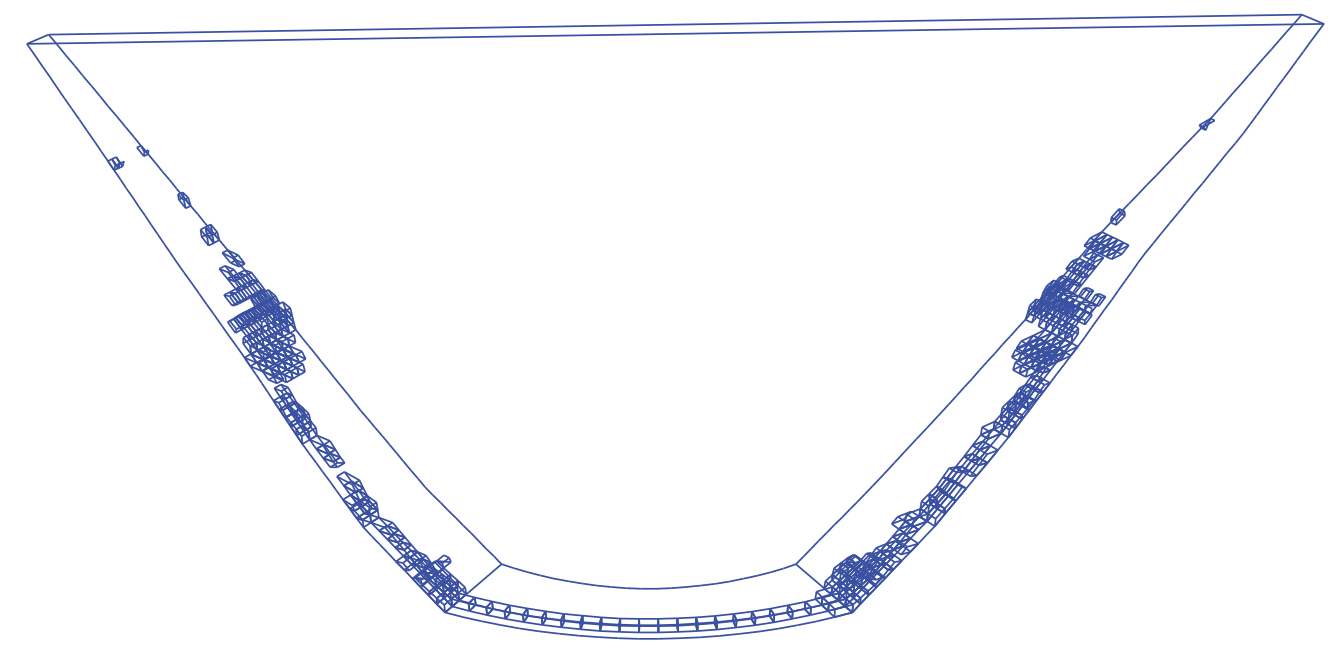

Figure 19: Distribution of cracked elements in dam when $R$ is equal to 0.3 .

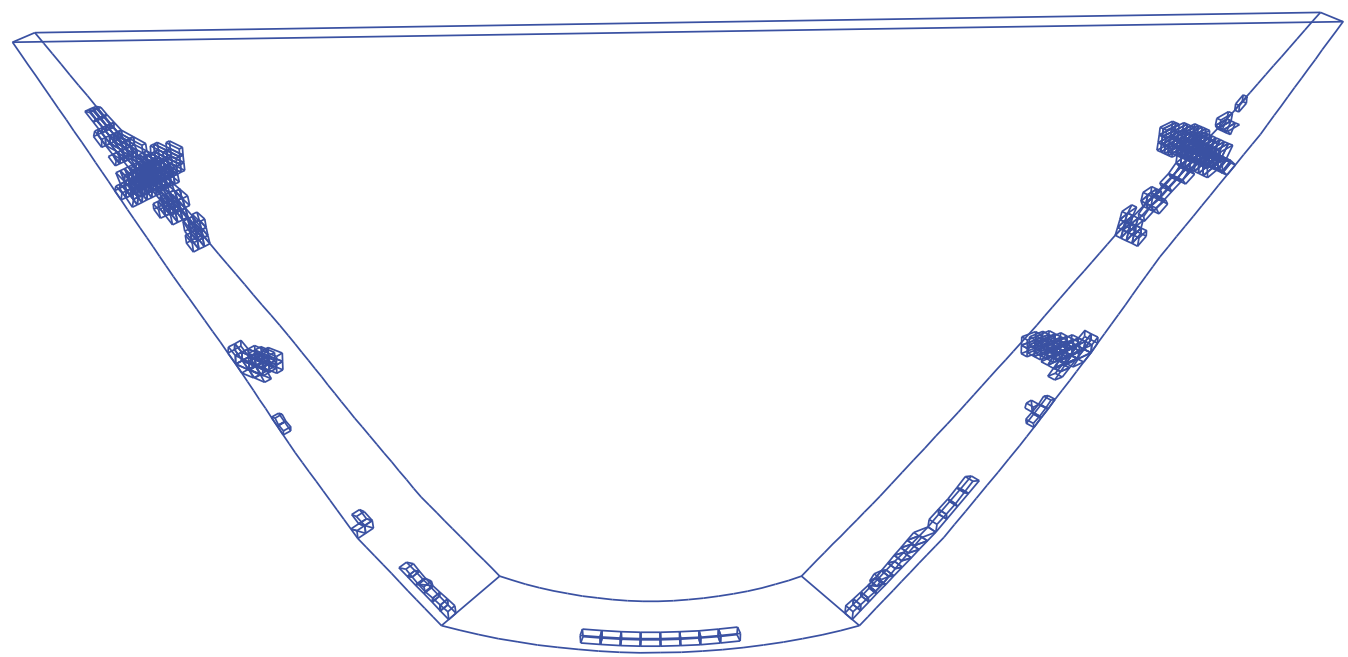

FIgURE 20: Distribution of cracked elements in dam when $R$ is equal to 0.1 .

Owing to the extremely low mechanical parameters of upper abutment used in the case of $R=0.1$, another type of failure mode (Mode III) can be observed. In Mode III, cracks are mainly distributed at the ends of upper arch rings, especially at the ends of arch rings with elevation of threequarters of dam height and around the interface between upper weak abutment and lower abutment, while only a small part of lower dam experiences cracking (see Figure 20 for the final distribution of cracked elements with the corresponding water pressure increased by 0.4 times). In other words, the failure behavior of the arch dam in Mode III is greatly influenced by the interaction between dam and upper weak abutment.

Overall, for the studied concrete arch dam, its cracking behavior and the associated failure mode change with the decrease of $R$, which is accompanied by a nonlinear reduction of the load-carrying capability (simply represented by the maximum water pressure reached in the simulation). From the structural design point of view, both Mode II and Mode
III should be avoided in practice since the dam safety is predominantly influenced by the weak upper abutment, and therefore the value of $R$ should be roughly larger than 0.5 based on the above discussion. As stated before, the failure behavior of the practical concrete arch dam can be considered to follow Mode II. Thus, engineering treatments are required to reinforce the weak upper abutment. Additionally, it is worth noting that the minimum value of $R$ for avoiding Mode II and Mode III is not the same for different concrete arch dams.

\section{Conclusions}

In the present work, the cracking behavior of a $78 \mathrm{~m}$ high concrete arch dam with weak upper abutment is detailed. Then, the influence of the ratio of the mechanical properties of upper abutment to those of lower abutment on dam failure mode is discussed by performing a sensitivity analysis. The work results in the following conclusions: 
(i) Based on the FE simulation results, the presented smeared crack model, which is feathered by modeling concrete cracking in an implicit manner at the constitutive level, is considered to be suitable for conducting the crack analysis of practical concrete arch dam.

(ii) The influence of the ratio of mechanical properties of upper abutment to those of lower abutment on the cracking behavior and load-carrying capacity of the concrete arch dam with weak upper abutment strongly depends on how small the ratio is, and three types of failure modes are identified through a comprehensive sensitivity analysis.

(iii) When the ratio is relatively high (less than 1.0), dam cracking and failure follow Mode I, and basically the upper abutment can directly serve as dam foundation without reinforcement. Adversely, when either Mode II or Mode III is followed, reinforcement of the weak upper abutment is required to increase the ratio.

(iv) For the real concrete arch dam with weak upper abutment, the failure mode can be considered to follow Mode II, and therefore engineering measures should be taken to increase the mechanical properties of weak upper abutment.

\section{Conflicts of Interest}

The authors declare that there are no conflicts of interest regarding the publication of this paper.

\section{Acknowledgments}

The research work presented herein was supported by the National Nature Science Foundation of China (Grant nos. 11132003, 51739006) and China Scholarship Foundation and Priority Academic Program Development of Jiangsu Higher Education Institutions, which are gratefully acknowledged.

\section{References}

[1] P. Lin, W. Y. Zhou, and H. Y. Liu, "Experimental study on cracking, reinforcement and overall stability of the Xiaowan superhigh arch dam," Rock Mechanics and Rock Engineering, 2014.

[2] B. S. Wang and Z. C. He, "Crack detection of arch dam using statistical neural network based on the reductions of natural frequencies," Journal of Sound and Vibration, vol. 302, no. 4-5, pp. 1037-1047, 2007.

[3] Z. Dongjian, H. Zhongyan, and L. Bo, "Arch-dam crack deformation monitoring hybrid model based on XFEM," Science China Technological Sciences, vol. 54, no. 10, pp. 2611-2617, 2011.

[4] W.-P. Fei, L. Zhang, and R. Zhang, "Experimental study on a geo-mechanical model of a high arch dam," International Journal of Rock Mechanics and Mining Sciences, vol. 47, no. 2, pp. 299-306, 2010.

[5] T. Yu and Q. Ren, "Evaluation of global safety degree of Jinping High Arch Dam," Chinese Journal of Rock Mechanics and Engineering, vol. 26, pp. 787-794, 2007.

[6] W. Zhou, R. Wang, and P. Lin, "Study on influences of asymmetry on arch dam foundation," Chinese Journal of Rock Mechanics and Engineering, no. 6, pp. 1081-1085, 2006.
[7] Y. Ning, W. Xu, W. Zheng, A. Shi, and G. Wu, "Reinforcement effect analysis and global safety evaluation of arch dam and abutment of baihetan hydropower station," Chinese Journal of Rock Mechanics and Engineering, vol. 27, pp. 1890-1898, 2008.

[8] B. Yang, L. Zhang, J. Chen, J. Dong, and C. Hu, "Experimental study of 3D geomechanical model for global stability of Xiaowan high arch dam," Chinese Journal of Rock Mechanics and Engineering, vol. 10, pp. 2086-2093, 2010.

[9] R. Espandar and V. Lotfi, "Comparison of non-orthogonal smeared crack and plasticity models for dynamic analysis of concrete arch dams," Computers \& Structures, vol. 81, pp. 1461$1474,2003$.

[10] R. Espandar, V. Lotfi, and G. Razaqpur, "Seismic analysis of concrete arch dams by combined discrete crack and nonorthogonal smeared crack technique," Engineering Structures, vol. 26, no. 1, pp. 27-37, 2004.

[11] H. N. Linsbauer, A. R. Ingraffea, H. P. Rossmanith, and P. A. Wawrzynek, "Simulation of crackingin large arch dam: part1," Journal of Structural Engineering, vol. 115, no. 7, pp. 1599-1615, 1989.

[12] H. N. Linsbauer, A. R. Ingraffea, H. P. Rossmanith, and P. A. Wawrzynek, "Simulation of cracking in large arch dam: Part ii," Journal of Structural Engineering, vol. 115, no. 7, pp. 1616-1630, 1989.

[13] M. A. Hariri-Ardebili, S. M. Seyed-Kolbadi, and H. Mirzabozorg, "A smeared crack model for seismic failure analysis of concrete gravity dams considering fracture energy effects," Structural Engineering and Mechanics, vol. 48, no. 1, pp. 17-39, 2013.

[14] J. Pan, Y. Feng, F. Jin, C. Zhang, and D. R. J. Owen, "Comparison of different fracture modelling approaches to gravity dam failure," Engineering Computations, vol. 31, no. 1, pp. 18-32, 2014.

[15] B. Van Rensburg, J. Robberts, and Q. Cai, "Cracking in concrete using smeared cracking finite element modelling," South African Journal of Science, vol. 102, pp. 548-556, 2006.

[16] M. Elices, G. V. Guinea, J. Gómez, and J. Planas, "The cohesive zone model: advantages, limitations and challenges," Engineering Fracture Mechanics, vol. 69, no. 2, pp. 137-163, 2001.

[17] I. Carol, P. C. Prat, and C. M. López, "Normal/shear cracking model: application to discrete crack analysis," Journal of Engineering Mechanics, vol. 123, no. 8, pp. 765-773, 1997.

[18] J. C. Gálvez, J. Červenka, D. A. Cendón, and V. Saouma, "A discrete crack approach to normal/shear cracking of concrete," Cement and Concrete Research, vol. 32, no. 10, pp. 1567-1585, 2002.

[19] J. G. Rots and J. Blaauwendraad, "Crack models for concrete: discrete or smeared? Fixed multi-directional or rotatin?" Heron, vol. 34, pp. 1-59, 1989.

[20] A. T. Slobbe, M. A. N. Hendriks, and J. G. Rots, "Smoothing the propagation of smeared cracks," Engineering Fracture Mechanics, vol. 132, pp. 147-168, 2014.

[21] A. Hillerborg, M. Modéer, and P.-E. Petersson, "Analysis of crack formation and crack growth in concrete by means of fracture mechanics and finite elements," Cement and Concrete Research, vol. 6, no. 6, pp. 773-781, 1976.

[22] Z. P. Bažant and B. H. Oh, "Crack band theory for fracture of concrete," Materials and Structures, vol. 16, no. 3, pp. 155-177, 1983.

[23] ABAQUS, ABAQUS 6.5 User's Manual, ABAQUS, Inc., 2004.

[24] H. Kupfer, H. K. Hilsdorf, and H. Rusch, "Behavior of concrete under biaxial stresses," Journal of the American Concrete Institute, vol. 66, no. 8, pp. 656-666, 1969. 
[25] M. A. Crisfield, "Snap-through and snap-back response in concrete structures and the dangers of under-integration," International Journal for Numerical Methods in Engineering, vol. 22, no. 3, pp. 751-767, 1986.

[26] J. Pan, Y. Xu, F. Jin, and C. Zhang, "A unified approach for longterm behavior and seismic response of AAR-affected concrete dams," Soil Dynamics and Earthquake Engineering, vol. 63, pp. 193-202, 2014. 


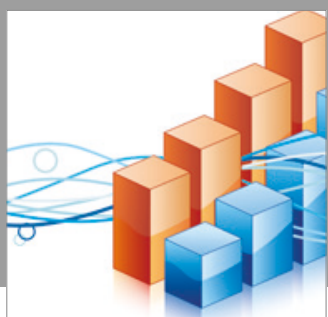

Advances in

Operations Research

vatersals

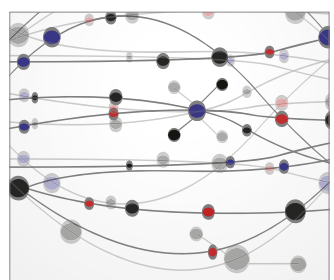

\section{The Scientific} World Journal
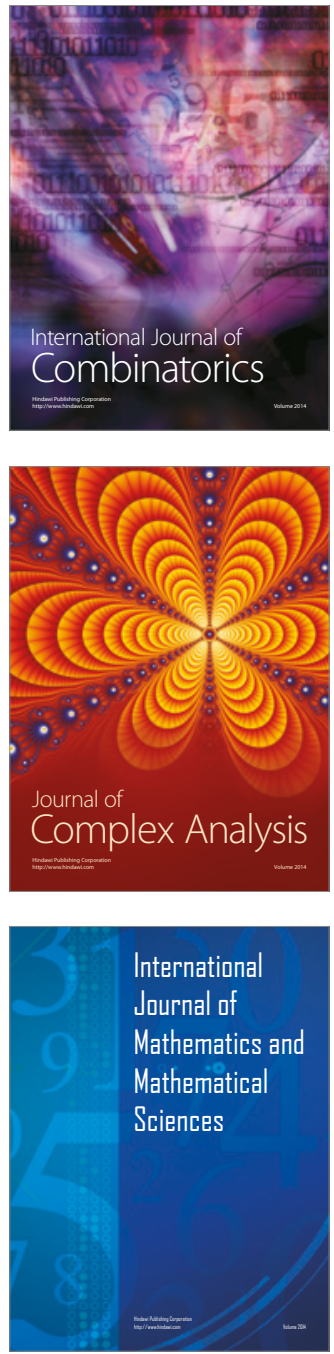
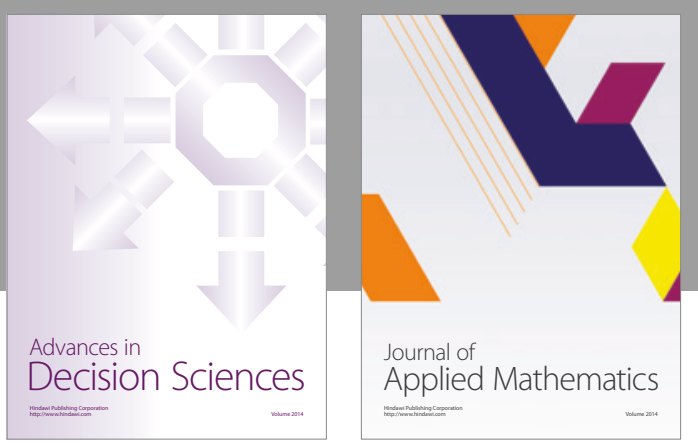

Algebra

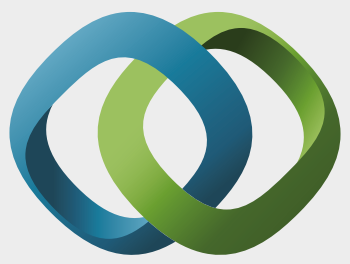

\section{Hindawi}

Submit your manuscripts at

https://www.hindawi.com
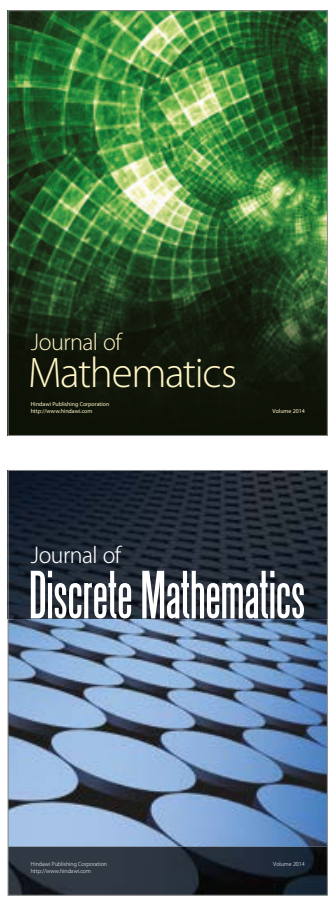

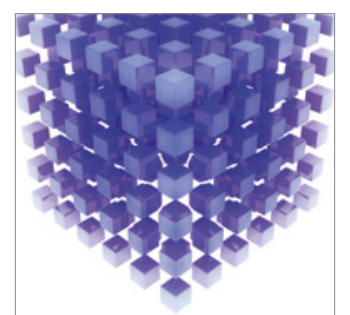

Mathematical Problems in Engineering
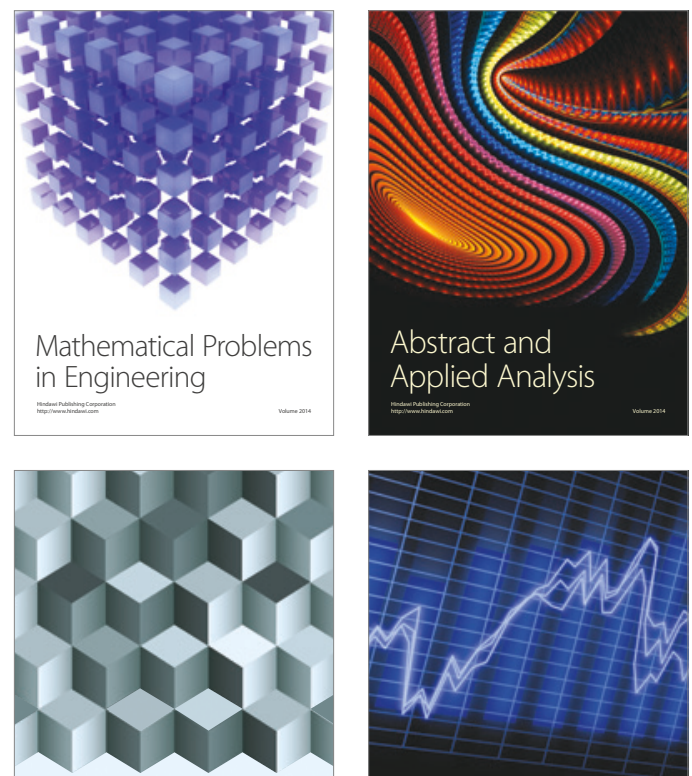

Journal of

Function Spaces

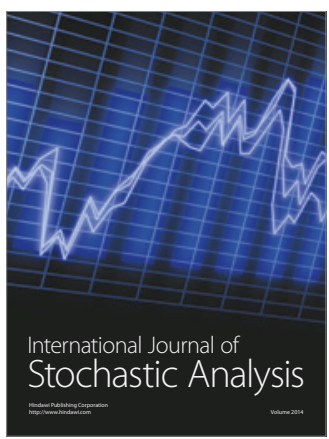

Probability and Statistics
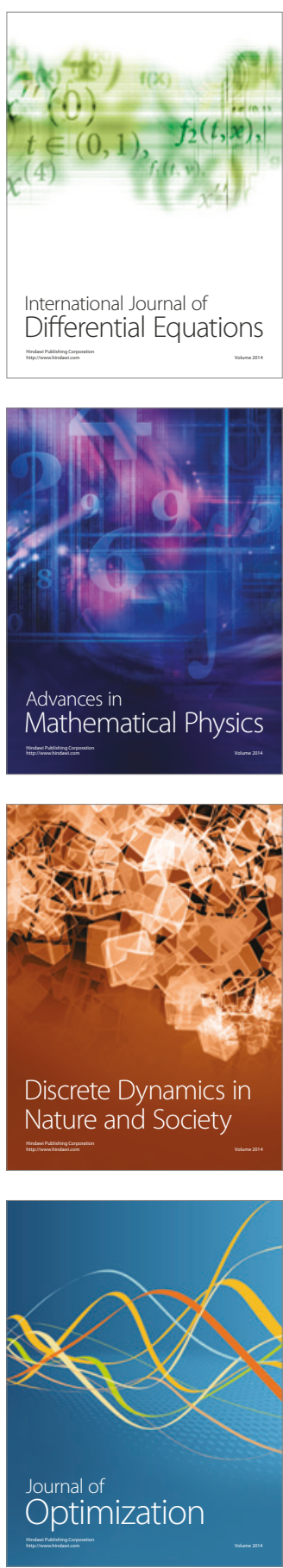